\title{
The effect of fibrin sealant on the prevention of seroma formation after postbariatric abdominoplasty
}

\author{
Johnson C Lee MD², Jason Teitelbaum $\mathrm{MS}^{2}$, Josh K Shajan BS², Aparajit Naram BS${ }^{2}$, Jerome Chao MD FACS ${ }^{3}$
}

\begin{abstract}
JC Lee, J Teitelbaum, JK Shajan, A Naram, J Chao. The effect of fibrin sealant on the prevention of seroma formation after postbariatric abdominoplasty. Can J Plast Surg 2012;20(3):178-180.
\end{abstract}

BACKGROUND: Seroma formation is one of the most common complications following abdominoplasty. Fibrin sealant/glue has shown mixed results in seroma prevention when used in a variety of procedures. Limited information is available on its effectiveness during postbariatric abdominoplasty.

METHODS: A retrospective chart analysis of 65 consecutive patients who underwent postbariatric abdominoplasty over a course of 16 months by a single surgeon was performed. Two sequential groups either receiving or not receiving fibrin sealant treatment were defined. Seroma formation and initial $24 \mathrm{~h}$ drain output volumes were recorded.

RESULTS: Three patients in group $1(9.1 \%)$ receiving fibrin sealant developed seroma. Twelve patients in group $2(28.1 \%)$ not receiving fibrin sealant developed seroma; this was statistically significant $(\mathrm{P}=0.006)$. Twenty-four hour drain output was also statistically different, with higher initial output in the fibrin sealant group $(222.2 \mathrm{~mL}$ versus $140.0 \mathrm{~mL}$; $\mathrm{P}=0.047$ ).

CONCLUSION: Fibrin sealant was a useful adjunct during surgical wound closure and significantly decreased seroma formation in patients undergoing postbariatric abdominoplasty.

Key Words: Abdominoplasty; Fibrin glue; Fibrin sealant; Seroma

Seroma formation remains one of the most common complications following abdominoplasty (1). The presence of a seroma may lead to the development of infection and cause significant disability by delaying recovery times and impairing normal wound healing (2). Current modalities for prevention and treatment of seroma include needle aspiration, doxycycline or bleomycin sclerotherapy, and the placement of drainage catheters (2). Although effective, these modalities are not without consequence. Prolonged drain placement can significantly increase the likelihood of bacterial infection and may become obstructed in the course of treatment, necessitating replacement. Furthermore, drains may directly interfere with proper wound healing (3). Lowering the risk of seroma formation and the duration of drain placement can further reduce complications of infection and impaired wound healing.

Fibrin sealant/glue is a readily available preparation that is believed to function by promoting closure of microvascular leaks caused by surgical trauma (4). Its use as a method for seroma prevention has been studied - with varying results - in mastectomy and rhytidectomy patients (3-8). In Germany, Toman et al (9) suggested that lowconcentration fibrin sealant may be effective in reducing seroma formation in the population undergoing abdominoplasty (9).

Although fibrin application has been used by surgeons worldwide for seroma prevention in abdominoplasty, no studies involving the United States postbariatric population currently exist to provide evidence for or against the use of fibrin sealant in this fashion (10). The purpose of the present study was to determine whether there

\section{L'effet de la colle de fibrine pour prévenir la} formation de sérome découlant d'une abdominoplastie après une chirurgie bariatrique

HISTORIQUE : La formation de sérome est l'une des principales complications après une abdominoplastie. La colle de fibrine, utilisée dans diverses interventions, donne des résultats mitigés dans la prévention du sérome. L'information relative à son efficacité lors d'une abdominoplastie après une chirurgie bariatrique est limitée.

MÉTHODOLOGIE : Les chercheurs ont procédé à l'analyse rétrospective des dossiers de 65 patients consécutifs qui, sur une période de 16 mois, ont subi une abdominoplastie après une chirurgie bariatrique. Ils ont défini deux groupes séquentiels, l'un recevant un traitement à la colle de fibrine et l'autre pas. Ils ont enregistré la formation de sérome et les volumes d'écoulement par le drain dans les 24 premières heures.

RÉSULTATS : Trois patients du groupe 1 (9,1\%) qui ont reçu de la colle de fibrine ont développé un sérome. Douze patients du groupe $2(28,1 \%)$ qui n'en avaient pas reçu en ont également développé un, ce qui est statistiquement significatif $(\mathrm{P}=0,006)$. L'écoulement par le drain sur 24 heures était également différent sur le plan statistique, l'écoulement initial étant plus important dans le groupe ayant reçu de la colle de fibrine (222,2 mL par rapport à 140,0 mL; P=0,047).

CONCLUSION : La colle de fibrine était un ajout utile pendant la fermeture chirurgicale de la plaie et réduisait considérablement la formation de sérome chez les patients qui subissaient une abdominoplastie après une chirurgie bariatrique.

is a significant reduction in seroma formation and immediate postoperative drainage output in postbariatric patients who have undergone abdominoplasty using fibrin sealant.

\section{METHODS}

After institutional review board approval, a retrospective chart review on all postbariatric abdominoplasty patients performed by a single senior surgeon (JDC) at the Albany Medical Center (Albany, USA) from June 2008 to September 2009, was conducted. All potential patients requesting elective abdominoplasty during this period were accepted for the surgical procedure regardless of comorbidities, body mass index (BMI), medication use, lifestyle or age, unless not medically cleared for general anesthesia by their primary care physician or the anesthesiologist. Data collected included age, sex, weight, height, BMI, application of fibrin sealant, $24 \mathrm{~h}$ drainage output, seroma formation and other complications.

Two sequential populations were compared: an early group of consecutive patients who underwent abdominoplasty without the application of fibrin sealant versus a group of consecutive patients who underwent abdominoplasty and received a complete application of $10 \mathrm{~mL}$ TISSEEL (Baxter, USA) fibrin sealant.

General anesthesia, sequential compression devices (SCD) and perioperative antibiotic prophylaxis were administered to all patients preoperatively. Skin flap elevation was performed with electrocautery in an identical fashion across all patients. No adjunctive procedures specific to the abdominal region including tumescent injection,

\footnotetext{
${ }^{1}$ Division of Plastic Surgery; ${ }^{2}$ Albany Medical College, Albany; ${ }^{3}$ Certified Plastic Surgery of New York, PLLC, Latham, New York, USA Correspondence: Dr Johnson C Lee, Division of Plastic Surgery, Albany Medical College, 43 New Scotland Avenue MC-190, Albany, New York 12208, USA. Telephone 518-262-4880, fax 518-262-5999, e-mail Johnsonlee1@gmail.com
} 
Figure 1) Incidence of seroma formation following postbariatric abdominoplasty. Group 1, fibrin sealant application ( $n=33$ [9.1\%]); Group 2, no fibrin sealant application $(n=32[28.1 \%])$. These rates were significantly different ( $P=0.006 ; \alpha=0.05$ [Fisher's exact test])

liposuction or quilting sutures were performed. In all patients who received fibrin sealant, fibrin sealant was prepared and applied per manufacturer recommendation over the abdominal fascia. An additional $20 \mathrm{~mL}$ of human recombinant thrombin was then sprayed for hemostasis. In all patients, Jackson-Pratt drains were placed in the dissection plane along the abdominal incision and a final multilayer skin closure was performed. Once discharged, all patients were assessed at weekly intervals by the performing surgeon who monitored for seroma formation and any associated complications, and removed drains as necessary.

Statistical analysis included the Fisher's exact test to measure differences in the number of seroma outcomes between the treatment groups, and the $t$ test to measure differences between means for age, weight, BMI and comparing rate of seroma formation between treatment groups as well as outcome groups. An unpaired two-sample $t$ test was used to measure significance of BMI and $24 \mathrm{~h}$ drainage output between the fibrin sealant group and those not treated with fibrin sealant.

\section{RESULTS}

A total of 65 patients underwent postbariatric abdominoplasty. The mean $( \pm$ SD) age of all patients in the sample was $49.5 \pm 11.1$ years. The mean weight of this group of patients was $93.4 \pm 26.2 \mathrm{~kg}$, with a mean BMI of $34.7 \mathrm{~kg} / \mathrm{m}^{2}$. The sample population included eight males and 57 females (Table 1).

Thirty-three procedures involved the application of fibrin sealant (group 1). The mean weight for group 1 was $87.4 \pm 18.6 \mathrm{~kg}$, with a mean age of $47.6 \pm 10.1$ years and an average BMI of $33.5 \mathrm{~kg} / \mathrm{m}^{2}$. Six males and 27 females comprised group 1.

The earlier 32 patients (group 2) underwent abdominoplasty without application of fibrin sealant. The mean weight for group 2 was $99.5 \pm 31.3 \mathrm{~kg}$, with a mean age of $51.4 \pm 11.8$ years and an average BMI of $36.4 \mathrm{~kg} / \mathrm{m}^{2}$. Two males and 30 females comprised group 2 .

Three patients in group 1 experienced seroma formation, representing $9.1 \%$ of the population; 12 patients in group 2 experienced seroma formation, representing $28.1 \%$ of the population. The proportion of patients that developed seroma in group 1 was found to be significantly different than the proportion of patients that developed seroma in group $2(\mathrm{P}=0.006 ; \alpha=0.05$, Fisher's exact test) (Figure 1$)$.

Results indicate that the use of fibrin sealant abdominoplasty is associated with a relative risk reduction $(R R R)$ of $68 \%(R R R=0.68)$ with regard to rates of seroma formation. The value of fibrin sealant use during abdominoplasty shows a significant reduction in seroma formation when performing at least five abdominoplasties (number needed to treat $=5$ ).

When comparing demographic data between the two groups, there were differences in average weight, age and BMI. Patients who formed seroma were, on average, younger (46.2 versus 50.2 years of age), heavier (102.9 $\mathrm{kg}$ versus $91.2 \mathrm{~kg})$, with higher BMIs $\left(36 \mathrm{~kg} / \mathrm{m}^{2}\right.$ versus $\left.34.4 \mathrm{~kg} / \mathrm{m}^{2}\right)$. These were not found to be statistically significant, even when controlling for the use of fibrin sealant (Table 1).
TABLE 1

Fibrin sealant application versus no fibrin sealant application outcomes

\begin{tabular}{|c|c|c|c|c|}
\hline & \multicolumn{2}{|c|}{ Fibrin sealant } & \multirow{2}{*}{$\begin{array}{c}\text { Difference } \\
(\alpha=0.05)\end{array}$} & \multirow{2}{*}{$\begin{array}{c}\text { All } \\
(n=65)\end{array}$} \\
\hline & Yes $(n=33)$ & No $(n=32)$ & & \\
\hline Weight, kg & $87.4(52-131)$ & $99.5(58-183)$ & & $93.4(52-183)$ \\
\hline Age, years & $47.6(26-64)$ & $51.4(26-81)$ & & $49.5(26-81)$ \\
\hline BMI, kg/m² & $33.5(20-78)$ & $36.4(24-61)$ & $\mathrm{P}=0.147^{*}$ & $34.7(20-78)$ \\
\hline \multicolumn{5}{|l|}{ Sex, $n$} \\
\hline Male & 6 & 2 & & 8 \\
\hline Female & 27 & 30 & & 57 \\
\hline \multicolumn{5}{|l|}{ Seroma formation } \\
\hline Outcomes, $\mathrm{n}$ & 3 & 12 & $\mathrm{P}=0.006^{\dagger}$ & 15 \\
\hline Age, years, mean & 47.3 & 45.7 & $P=0.83^{\ddagger}$ & $\begin{array}{c}46.2 \\
(P=0.25)^{\S}\end{array}$ \\
\hline Weight, kg, mean & 89.7 & 107.3 & $P=0.44^{\ddagger}$ & $\begin{array}{c}102.9 \\
(P=0.16)^{\S}\end{array}$ \\
\hline $\mathrm{BMI}, \mathrm{kg} / \mathrm{m}^{2}$, mean & 33.1 & 37.4 & $P=0.47^{\ddagger}$ & $36(P=0.95)^{\S}$ \\
\hline \multicolumn{5}{|l|}{ No complications } \\
\hline Outcomes, $\mathrm{n}$ & 30 & 20 & $P=0.006^{\dagger}$ & 50 \\
\hline Age, years, mean & 47.3 & 53.5 & $P=0.06^{\ddagger}$ & 50.2 \\
\hline Weight, kg, mean & 89.7 & 96.4 & $P=0.17^{\ddagger}$ & 91.2 \\
\hline $\mathrm{BMI}, \mathrm{kg} / \mathrm{m}^{2}$, mean & 33.4 & 35.5 & $P=0.52^{\ddagger}$ & 34.4 \\
\hline $\begin{array}{l}24 \text { h drain output, } \\
\mathrm{mL}\end{array}$ & $\begin{array}{c}222.2 \\
(35-410)\end{array}$ & $\begin{array}{c}140.0 \\
(69-211)\end{array}$ & $\mathrm{P}=0.047^{*}$ & 189.3 \\
\hline
\end{tabular}

Data presented as mean (range) unless otherwise indicated. *Unpaired twosample $\mathrm{t}$ test $(\alpha=0.05)$; †Fisher's exact test $(\alpha=0.05) ; \mathrm{t}$ test, difference in means for age, weight, body mass index (BMI) comparing rate of seroma formation to no complications, controlling for fibrin sealant application; \$t test, difference in means for age, weight, BMI comparing rate of seroma formation with no complications

The average $24 \mathrm{~h}$ drainage output in patients receiving fibrin sealant was $222.2 \pm 187.7 \mathrm{~mL}$ following abdominoplasty. Patients who did not receive fibrin sealant produced an average $24 \mathrm{~h}$ drainage output of $140 \pm 71 \mathrm{~mL}$ days postoperatively. The difference in the mean volumes was significant ( $\mathrm{P}=0.047 ; \alpha=0.05$ [unpaired two-sample $t$ test]).

Other minor complications included skin and fat necrosis, swelling, hematoma, open wounds, rashes and cellulitis. Major complications included new pannus development and scrotal swelling.

\section{DISCUSSION}

Seroma formation frequently complicates the healing course following panniculectomy and is often considered to be a serious complication if it requires multiple aspirations, replacement of indwelling drainage, sclerosis or reoperation. The incidence of seroma formation can be erratic: some studies report incidences of only $5 \%$, while others report rates as high as $25 \%$, with higher rates particularly found in the postbariatric population $(1,11)$. It is, therefore, both necessary and recommended that a standard protocol be developed to provide a reduction in seroma formation incidence and improved healing times.

In our study, data from consecutive patients was examined to evaluate the use of fibrin sealant. Although retrospective in nature, the earlier group of patients acted as a control after a point in time when the senior surgeon decided to include fibrin sealant application to his standard technique in all subsequent postbariatric abdominoplasty patients in an attempt to reduce seroma formation. No changes to selection criteria were made and there were no statistical differences in age, weight and BMI between the two groups.

TISSEEL fibrin sealant was used in all patients. TISSEEL is a mixture largely composed of fibrinogen, fibrinolysis inhibitor solution, human thrombin and calcium chloride solution. Although TISSEEL itself contains 400 units to 625 units of human thrombin/mL, all patients received an additional $20 \mathrm{~mL}$ application of recombinant 
human thrombin for hemostasis and technical preference of the senior surgeon. In both human and rat models, it has been reported that thrombin alone does not significantly reduce seroma formation $(12,13)$. Our results, therefore, indicate that the significant reduction in seroma formation is likely due to the contribution of the fibrin component of the sealant and that thrombin does not contribute significantly.

Fibrin sealant has been shown to improve seroma formation via three mechanisms (12). Fibrin glue seals microvascular and connective tissue injuries that typically result from invasive surgery, dramatically reducing fluid retention that can lead to serious complications. The glue seals tissue to wound surfaces, thereby decreasing the threedimensional space that results from surgical invasion in which seromas may develop. Application of fibrin sealant also enables faster revascularization of wounded tissue across suture lines, increasing healing integrity. With our technique, fibrin sealant was applied widely and superficially over the abdominal fascia in the plane of dissection. This prevents superfluous activation of the coagulation pathway that might have occurred with an intravascular approach.

Fibrin sealant has been used successfully in seroma prevention in other surgical procedures. In axillary lymphadenectomy for breast cancer, it has been shown to decrease the magnitude of the seroma without reducing the incidence (14). Aside from decreasing seroma rates, fibrin glue has also benefited rhytidectomy patients by eliminating the use of drains, decreasing postoperative inflammation and preventing ecchymoses (6). While the literature offers a limited demonstration of fibrin use in treating abdominoplasty patients, we believe that the present brief review offers promising results and that further studies should be undertaken to determine the extent of its applicability.

Further studies are warranted to examine cost effectiveness, the effects of confounding variables, such as comorbidities and medication use, the effects of sex, and the effects on drainage rates and other known complications. Interestingly, we demonstrated a statistically significant difference in drainage output, with greater $24 \mathrm{~h}$ drainage output in those treated with fibrin sealant. We hypothesize that this observation may be due to the ability of fibrin sealant to reduce the amount of free space between the skin flap and abdominal wall. Fluid then drains more rapidly given a smaller volume in which it may accumulate, which would also correlate with a decrease in the seroma

\section{REFERENCES}

1. Stewart KJ, Stewart DA, Coghlan B, et al. Complications of 278 consecutive abdominoplasties. J Plast Reconstr Aesthet Surg 2006;59:1152-5.

2. Shermak MA, Rotellini-Coltvet LA, Chang D. Seroma development following body contouring surgery for massive weight loss: Patient risk factors and treatment strategies. Plast Reconstr Surg 2008;122:280-8.

3. Moore M, Burak WE Jr, Nelson E, et al. Fibrin sealant reduces the duration and amount of fluid drainage after axillary dissection: A randomized prospective clinical trial. J Am Coll Surg 2001;192:591-9.

4. Sanders RP, Goodman NC, Amiss LR Jr, et al. Effect of fibrinogen and thrombin concentrations on mastectomy seroma prevention. J Surg Res 1996;61:65-70.

5. Carless PA, Henry DA. Systematic review and meta-analysis of the use of fibrin sealant to prevent seroma formation after breast cancer surgery. Br J Surg 2006;93:810-9.

6. Kamer FM, Nguyen DB. Experience with fibrin glue in rhytidectomy. Plast Reconstr Surg 2007;120:1045-52.

7. Mortenson MM, Xing Y, Weaver S, et al. Fibrin sealant does not decrease seroma output or time to drain removal following inguinofemoral lymph node dissection in melanoma patients: A randomized controlled trial (NCT00506311). World J Surg Oncol 2008;6:63.

8. Ruggiero R, Procaccini E, Piazza P, et al. Effectiveness of fibrin glue in conjunction with collagen patches to reduce seroma formation formation rate. Our general practice is to wait three weeks until removing the drains from the abdomen. Although extended Jackson-Pratt drain placement may be associated with an increased risk of infection, we believe that this risk is offset by the benefits of removing exudate, which may cause a more noxious complication. There were also only eight males in the study, representing $12 \%$ of the sample population. The typical patient in the present study was an overweight, middle-age woman. It is, therefore, prudent to study the application of fibrin on a more diverse patient group to determine whether the same conclusion can be reached. At the time of the present study, TISSEEL fibrin sealant incurred a cost of approximately $\$ 300 /$ application and its cost effectiveness has not yet been evaluated in abdominoplasty patients (15). Additionally, further research to evaluate its effect, if any, on other complications, such as cellulitis, fat necrosis and wound dehiscence, would help determine the cost effectiveness of the application, given our focus on seroma formation in the present study. Finally, a prospective, blinded study in a larger study population including the effects of fibrin, given other wound-healing variables such as medications, comorbidities and nutritional status, would prove beneficial, although we believe that our nearly 'all-inclusive' selection criteria after medical clearance allows us to apply the findings of the present study to the general postbariatric patient population seen at our regional hospital.

\section{CONCLUSION}

In our experience with 65 consecutive postbariatric abdominoplasty procedures, we found that the application of fibrin sealant at surgical closure significantly reduced the rate of seroma formation. Complication rates following invasive surgeries, particularly abdominoplasty, frequently complicate the healing course and present significant burdens to patients and surgeons. Seroma formation, while not as severe as other complications, is a very frequent problem. Patient safety, satisfaction and health outcomes can be significantly improved in patients undergoing abdominoplasty or similar procedures by reducing seroma formation with the application of fibrin spray around the fascia at surgical closure. The plastic surgery faculty at Albany Medical Center has found fibrin sealant to be a useful adjunct in the surgical armamentarium for preventing complications. The continued use of the fibrin sealant is expected for all abdominoplasty patients.

after axillary lymphadenectomy for breast cancer. Am J Surg 2008;196:170-4.

9. Toman N, Buschmann A, Muehlberger T. [Fibrin glue and seroma formation following abdominoplasty]. Chirurg 2007;78:531-5.

10. Jones GG, Saour S, Botha AJ, Healy CM. Surgical tip - a novel method of applying fibrin sealant during repair of divarication of the recti via an abdominoplasty incision. J Plast Reconstr Aesthet Surg 2009;62:e457-8.

11. Larsen M, Polat F, Stook FP, et al. Satisfaction and complications in post-bariatric surgery abdominoplasty patients. Acta Chir Plast 2007;49.4:95-8.

12. Lindsey W, Becker D, Cantrell R, et al. Comparison of topical fibrin glue, fibrinogen, and thrombin in preventing seroma formation in a rat model. Laryngoscope 1995;105.3:241-3.

13. Burak W, Goodman P, Young D, et al. Seroma formation following axillary dissection for breast cancer: Risk factors and lack of influence of bovine thrombin. J Surg Oncol 1997;64.1:27-31.

14. Ruggiero R, Procaccini E, Gili S, et al. New trends on fibrin glue in seroma after axillary lymphadenectomy for breast cancer. G Chir 2009;30.6-7:306-10.

15. Figueras J, Llado L, Miro M, et al. Application of fibrin glue sealant after hepatectomy does not seem justified. Ann Surg 2007;245.4:536-42. 